\title{
STABILISASI TANAH EKSPANSIF MENGGUNAKAN KOLOM GARAM DENGAN PENGALIRAN SAMPING
}

\author{
Alif Muzakki ${ }^{1)}$, Bambang Setiawan ${ }^{2)}$, Niken Silmi ${ }^{2)}$ \\ 1)Mahasiswa Fakultas Teknik, Prodi Teknik sipil, Universitas Sebelas Maret \\ 2) Pengajar Fakultas Teknik, Prodi Teknik sipil, Universitas Sebelas Maret \\ Jl. Ir. Sutami 36A, Surakarta 57126; Telp 0271-634524. Email: ikkazum17@gmail.com
}

\begin{abstract}
ABSTRAK
Tanah merupakan dasar dari semua konstruksi baik berupa gedung maupun jalan. Permasalahan yang sering dihadapi pada konstruksi jalan diatas tanah Ekspansif adalah potensi pengembangan yang besar, dan daya dukung tanah yang rendah. Berbagai cara dilakukan untuk memperbaiki sifat dari tanah ekspansif, diantaranya dengan penambahan kolom garam (stabilisasi secara kimiawi). Tujuan dari penelitian ini adalah untuk memperbaiki potensi pengembangan (swelling) yang besar dengan menggunakan kolom garam. Pengujian tanah yang dilakukan meliputi uji pengembangan (swelling) dengan masa perawatan selama 20 hari, uji Atteberg limit, uji batas kuat tekan dan uji mineralogi. Kolom garam (NaCl) sebagai bahan stabilisasi yang di letakkan didalam drum dengan pengaliran dari sisi samping drum. Sampel tanah lempung ekspansif diambil dari area proyek jalan tol Solo-Kertosono, sedangkan sampel garam yang dipakai adalah garam grasak dengan pengaliran selama 20 hari.. Hasil penelitian adalah penambahan kolom garam dapat mengurangi nilai potensi mengembang dan memperbaiki daya dukung tanah ekspansif. Penambahan kolom garam dapat mereduksi nilai pengembangan sampai 15,38 \%. Penambahan garam dapat menurunkan indeks plastisitas dari 71,76\% menjadi 59,11\% dan memperbaiki nilai kuat tekan dari $6,98 \mathrm{kN} / \mathrm{m} 2$ menjadi $77,14 \mathrm{kN} / \mathrm{m} 2$.
\end{abstract}

Kata kunci : tanah ekspansif, kolom garam, pengembangan.

\begin{abstract}
Soil is base of all constructions due to buildings and highway. Most of the problems that faced by road construction on expansive soil is a great potential for swelling and capacity low ground. Many ways to be done to improve the nature of expansive soil, include a column with the addition of salt (chemical stabilization). Soil testing include swelling test with the period of treatment for 20 days, atteberg limits, unconfined compression test, and mineralogy test. Column salt ( $\mathrm{NaCl}$ ) as a stabilizer that put inside a drum with actually side of the side of a drum. Loam soil samples expansive taken from an area of toll road projects solo-kertosono, While salt sample used is a salt actually grasak. With flowing for 20 days. The results are adding column salt can reduce the potential of swelling and improve the soil expansive capacity. The addition of column salt can reduce value of swelling until $15.38 \%$. Addition of salt can degrade index plasticity of 71,76 become $59,11 \%$ \% and fix the value of strong press from $6,98 \mathrm{kN} / \mathrm{m} 2$ being $77,14 \mathrm{kN} / \mathrm{m} 2$
\end{abstract}

Keywords : expansive soil, salt column, swelling

\section{PENDAHULUAN}

Tanah adalah aspek penting dalam pembangunan dikarenakan hampir semua bangunan berdiri diatas tanah dan berfungsi sebagai tempat dimana pondasi suatu bangunan yang akan menentukan kekuatan bangunan diatasnya.. Tanah ekspansif adalah salah satu jenis tanah yang bermasalah kareana memiliki sifat kembang susut. Terjadinya pengembangan dan penyusutan pada tanah menjadi sangat berbahaya, terlebih lagi apabila di atas tanah tersebut akan berdiri bangunan sipil. Tanah seperti ini tergolong tanah yang tidak stabil sehingga dapat merusak lantai bangunan yang akan didirikan, atau yang lebih berbahaya dapat merusak pondasi bangunan tersebut. Potensi kembang-susut pada Tanah ekspansif umumnya diakibatkan oleh perubahan kadar air sehingga menyebabkan perubahan volume tanah. Perubahan volume tanah akibat kadar air yang rendah dapat mengakibatkan penurunan pada bangunan di atasnya (settlement). Kadar air yang tinggi dalam tanah dapat pula mengakibatkan tanah mengembang sehingga dapat menyebabkan bangunan terangkat (uplift), Oleh sebab itu, untuk memperbaiki tanah ekspansif peneliti menggunakan perbaikan dengan cara kimiawi yaitu dengan menambah kolom garam. Penggunaan kolom dikarenakan pada penelitian sebelumnya digunakan perbaikan dengan cara garam disebarkan pada tanah ekspansif oleh karena itu peneliti ingin membuat inovasi baru dengan menggunakan kolom. Penggunaan garam pada perbaikan tanah ekspansif diganakan karena garam menaikkan kepadatan dan menambah kekuatan tanah dengan penyebaran ketika garam bereaksi dengan air dan menyebar ke dalam tanah. Tanah dengan LL (liquit limits) yang tinggi biasanya memberikan reaksi yang bagus dengan penambahan garam ini. 


\section{TINJAUAN PUSTAKA DAN LANDASAN TEORI}

\section{Tanah ekspansif}

Tanah lempung ekspansif adalah tanah yang mempunyai potensi kembang yang besar. Peningkatan kadar air tanah akan mengembang disertai dengan peningkatan tekanan air pori dan timbulnya tekanan pengembangan dan sebaliknya apabila kadar air berkurang akan terjadi penyusutan. Mineral lempung terdiri dari tiga komponen penting yaitu montmorillonite, illite dan kaolinite. Karena mempunyai sifat yang merusak dibutuhkan upaya stabilisasi untuk memperbaiki tanah tersebut. Salah satu upaya stabilisasi adalah dengan melakukan penambahan zat aditif ke dalam tanah, Hakim (2015). Mineral yang biasa terdapat pada tanah ekspansif adalah montmorilonite, kaolinite, dan illite. Hasil penelitian sebelumnya memberikan konfirmasi bahwa masalah terbesar terjadi pada tanah ekspansif dengan kandungan montmorilonite tinggi. Metode yang dilakukan untuk mengetahui indentifikasi tanah ekspansif pada penelitian ini antara lain adalah identifikasi minerologi, uji gradasi tanah, berat spesifik tanah, korelasi atterberg limits, korelasi potensi pengebangan dengan sifat sifat indeks. Pengujian uji kuat tekan bebas digunakan untuk menentukan besar kohesi atau kuat geser tanah.

Pengujian untuk mencari parameter kuat geser tanah, pengujian ujikuat tekan bebas hanya cocok untuk jenis tanah lempung jenuh, dimana pada pembebanan cepat, air tidak sempat mengalir keluar dari benda uji. Kadar air, dinyatakan dalam persen dimana terjadi transisi dari keadaan padat ke keadaan semi-padat didefiniskan sebagai batas susut (shrinkage limit). Kadar air di mana trasnsisi dari keadaan semi-padat ke keadaan plastis terjadi dinamakan batas plastis (plastic limit) dan dari keadaan plastis ke keadaan cair dinamakan batas cair (liquid limit). Batas batas ini dikenal juga sebagai batas batas Atterberg (Atterberg Limits).Pengujian pengembangan dilaksanakan sebagai tolak ukur bagaimana penambahan zat kimia bisa merubah sifat mengembang dari tanah ekspansif. Hardiyatmo (2014).

\section{Stabilisasi tanah ekspansif dengan kolom garam}

Menurut Bowles, (1985) beberapa tindakan yang dilakukan untuk menstabilisasikan tanah adalah sebagai berikut: meningkatkan kerapatan tanah, menambah material yang tidak aktif sehingga meningkatkan kohesi dan/atau tahanan gesek yang timbul, menambah bahan untuk menyebabkan perubahan-perubahan kimiawi dan/atau fisis pada tanah, menurunkan muka air tanah (drainase tanah), mengganti tanah yang buruk.

Garam adalah senyawa ionik yang terdiri dari ion positif (kation) dan ion negatif (anion), sehingga membentuk senyawa netral (tanpa bermuatan). Garam terbentuk dari hasil reaksi asam dan basa. Natrium Klorida $(\mathrm{NaCl})$. Bowles, (1985), selain itu larutan ini bisa memudahkan didalam memadatkan tanah.

Keuntungan yang dihasilkan adalah stabilisasi tanah lempung ekspansif dengan garam dapur $(\mathrm{NaCl})$ menaikkan kepadatan dan menambah kekuatan tanah dengan penyebaran ketika garam bereaksi dengan air dan menyebar ke dalam tanah. Tanah dengan LL (liquit limits) yang tinggi biasanya memberikan reaksi yang bagus dengan penambahan garam ini.

\section{METODE PENELITIAN}

Lokasi pengaambilan tanah ekspansif (expansive soil) adalah area proyek jalan tol Solo-Kertosono / Ruas Solo-Ngawi / Paket SNJ-2A / Sta. 76+900, Desa Jenggrik, Kecamatan Kedunggalar, Ngawi, Jawa Timur.

Penelitian yang pertama dilakukan adalah uji pendahuluan meliputi uji Grain size analysis, Atterberg limit, Spesific gravity, dan uji kandungan material. Pengujian utama menggunakan drum sebagai wadah tanah ekspansif kemudian membuat drainase samping melingkari tanah uji dengan menggunakan cetakan. Membentuk kassa berdiameter (D) $=5 \mathrm{~cm}$ pada tanah untuk menempatkan kolom garam dan dilakukan pemeraman selama 20 hari. Proses instalasi kolom garam dilakukan pada jarak antar kolom $(\mathrm{L})=2,75 \times$ Diameter $(\mathrm{D})$ dari kolom pusat, dan kedalaman $\left(\mathrm{D}_{\mathrm{f}}\right)$ $=4 \times$ Diameter $(\mathrm{D})$, kemudian menentukan letak titik pengamatan. Letak titik pengamatan dapat dilihat pada Gambar 1 

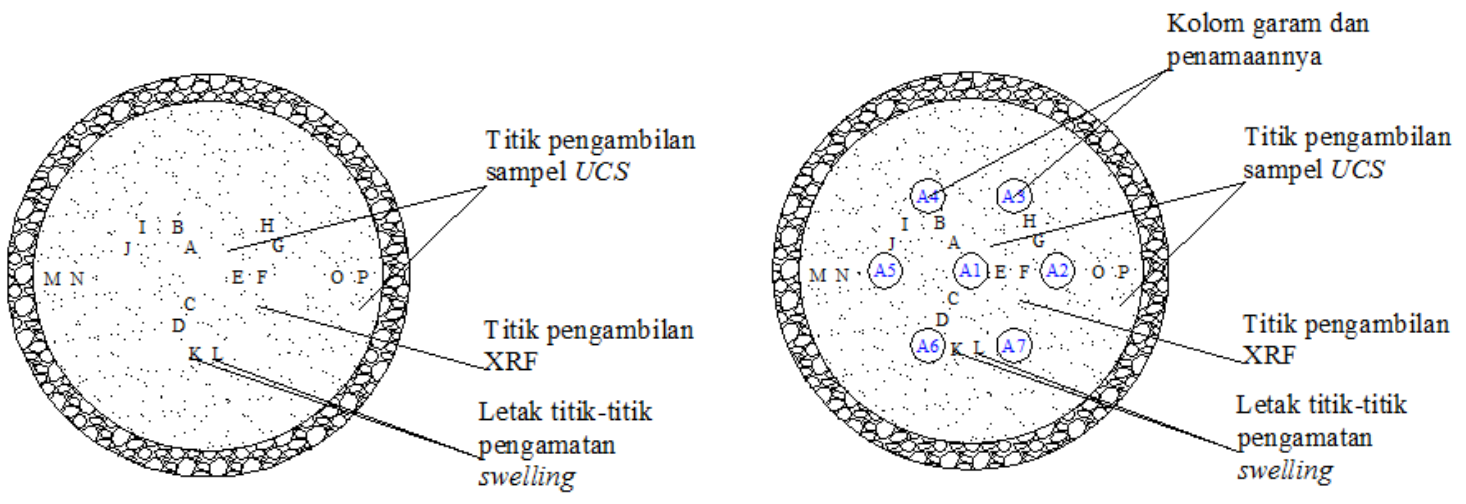

Gambar 1 Letak titik pengamatan pada tanah tanpa dan dengan perkuatan kolom

Gambar 1 di atas merupakan sketsa pengujian drum yang menggunakan kolom. Jarak antar kolom pusat ke samping $8,75 \mathrm{~cm}$ dan jarak antar kolom samping $5,52 \mathrm{~cm}$. Kolom garam yang digunakan memiliki diameter $5 \mathrm{~cm}$. Pengairan dilakukan melalui samping menuju ke arah kolom. Pengairan dilakukan secara periodic, bahan dari drainase ini berasal dari kawat kasa.
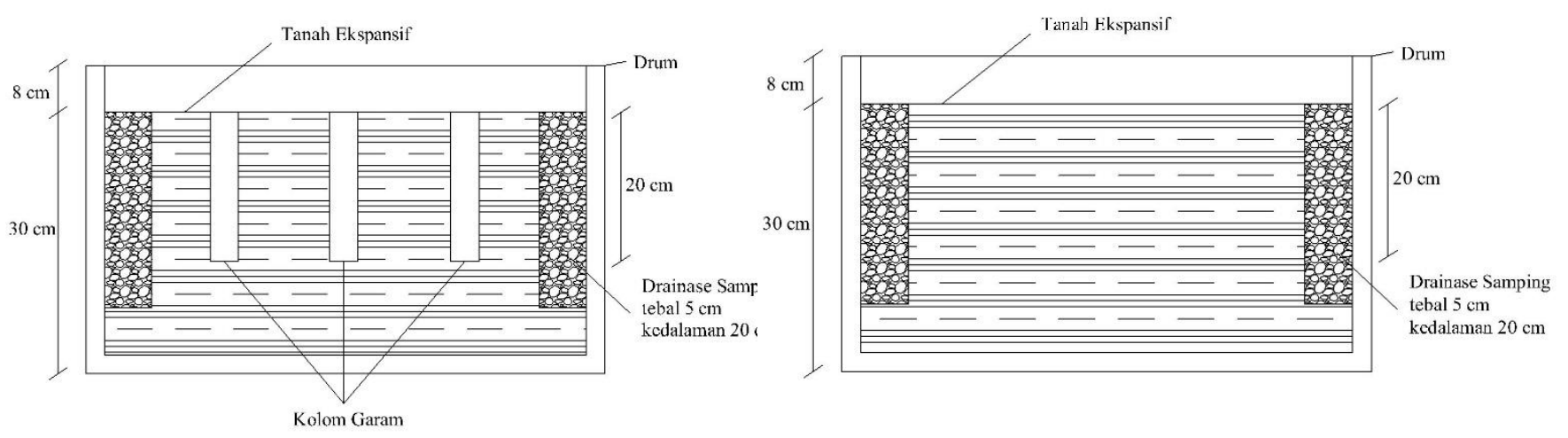

Gambar 2 Tampak samping tanah ekspansif pada drum uji dengan tanpa dan dengan kolom garam

Gambar 2 diatas merupakan sketsa potongan melintang pada drum yang menggunakan kolom garam. Pengairan akan dilakukan pada pinggiran drum dengan drainase yang ada pada pinggiran drum. Pengairan yang dilakukan pada pinggiran drum tersebut diharapkan akan menyebar kearah kolom melalui samping kolom.

\section{HASIL DAN PEMBAHASAN}

\section{Perbandingan pengembangan tanah}

Pengembangan yang terjadi setelah pembasahan selama 20 hari pada tanah ekspansif tanpa kolom garam rata-rata diatas 30\% pada zona 1 dan 2, sedangkan titik yang berada di zona 3 hanya diatas 10\%. Pada tanah ekspansif yang menggunakan kolom garam, besarnya pengembangan yang terjadi setelah pengembangan rata-rata diatas 20\% pada titik yang berada di tengah drum, sedangkan titik yang berada di tepi drum hanya diatas $10 \%$. Hal ini sesuai dengan penelitian Sudjianto (2006) menunjukkan semakin besar presentase garam di sekitar tanah pada area dalam akan menghasilkan reduksi swelling yang besar. Pembahasan akan dibagi menjadi 3 yaitu pembahasan titik yang berada pada zona 1, zona 2 dan zona 3 karena pada area masing masing terjadi perpindahan vertikal yang besar dan pada zona 3 titik P mengalami reduksi yang sangat kecil. Area pembahasan dapat dilihat pada Gambar 3. 

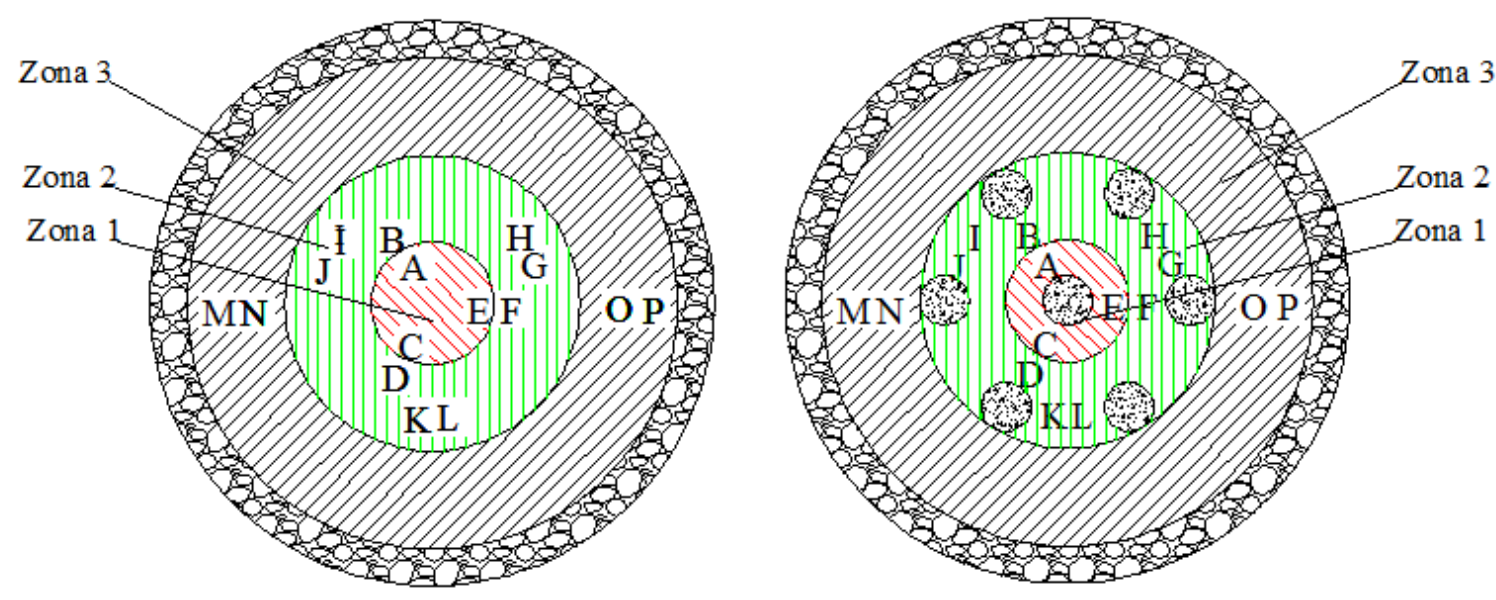

Gambar 3 Pembagian area pembahasan

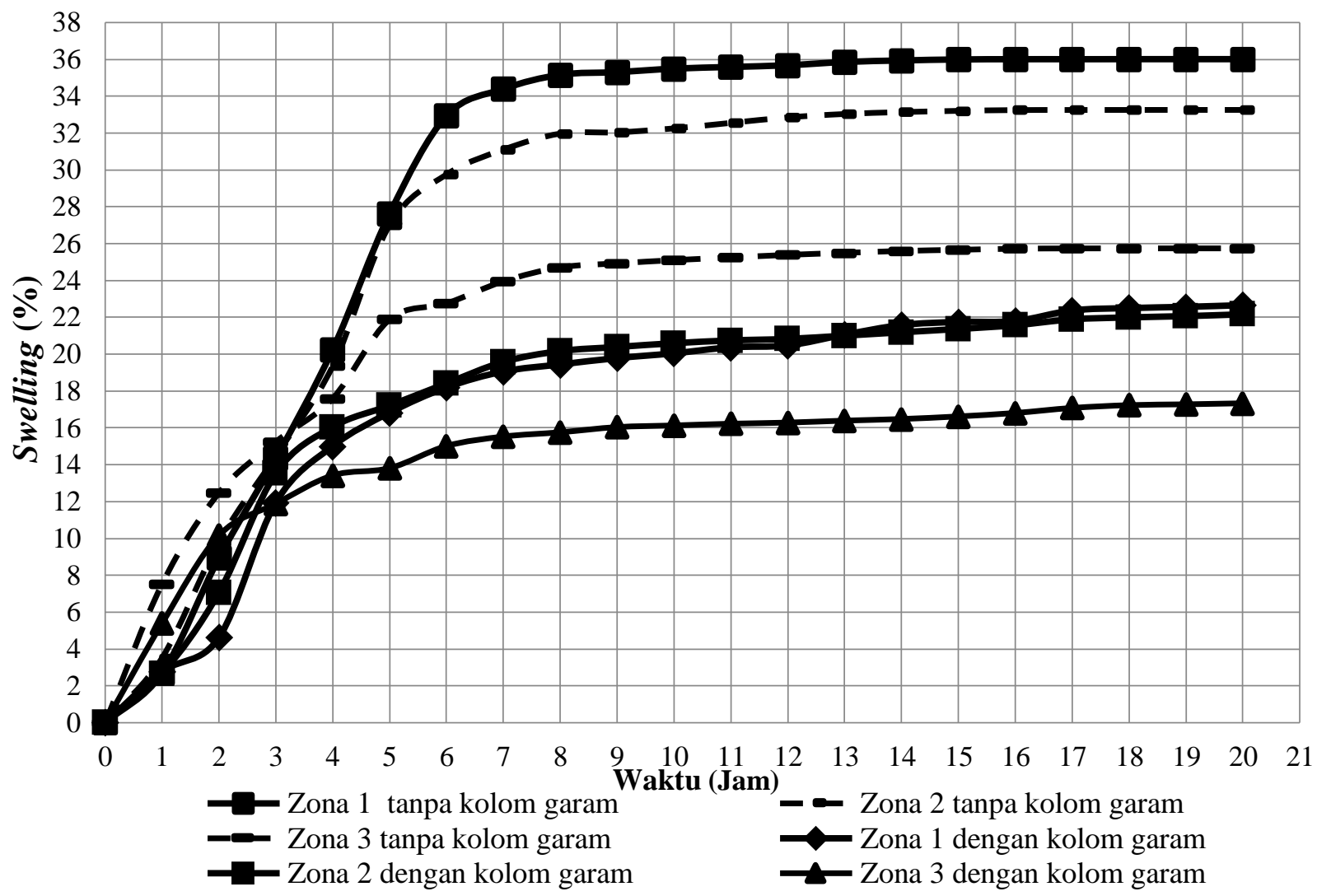

Gambar 4 Pengembangan rata-rata tanah ekspansif setiap zona

Perbandingan pengembangan pada zona 1 meliputi titik A, C, E mempunyai karakteristik pengembangan yang sama dan memiliki nilai pengembangan rata-rata 13,35\%. Titik A mengalami reduksi pengembangan terbesar yaitu 15,38 \% dan terdapat ditengah kolom. Perbandingan pengembangan pada zona 2 meliputi titik B, D, F, G, H, I, J, K, L mempunyai karakteristik pengembangan yang samadan mempunyai nilai pengembangan rata-rata $11,09 \%$. Titik B mengalami reduksi pengembangan terbesar yaitu 14,84\% dan terdapat di antara kolom. pengembangan pada zona 3 meliputi titik M, N, O, P mempunyai karakteristik pengembangan yang hamper sama dan mempunyai nilai pengembangan rata-rata $8,41 \%$. Titik $\mathrm{P}$ mengalami reduksi pengembangan terkecil yaitu $0,39 \%$ dan terletak jauh dari kolom. Gambar 4 menunjukkan bahwa pengembangan pada tanah ekspansif tanpa perkuatan kolom lebih besar daripada dengan kolom garam. Hasil reduksi pada kolom garam sesuai dengan penelitian dari Herman 
(2015), larutan garam merupakan larutan elektrolit yang mempunyai gerakan brown yang bisa menambah gaya kohesi antar partikel sehingga ikatan antar partikel lebih rapat. Adapun perbandingan swelling ditunjukkan Tabel 1

Tabel 1 Perbandingan rata-rata reduksi swelling

\begin{tabular}{|c|c|c|c|c|c|c|c|c|c|c|c|c|c|c|c|c|}
\hline Daerah & \multicolumn{3}{|c|}{ Zona 1} & \multicolumn{9}{|c|}{ Zona 2} & \multicolumn{4}{|c|}{ Zona 3} \\
\hline Titik & $\mathrm{A}$ & $\mathrm{C}$ & $E$ & B & $\mathrm{D}$ & $\mathrm{F}$ & $\mathrm{G}$ & $\mathrm{H}$ & I & $\mathrm{J}$ & $\mathrm{K}$ & $\mathrm{L}$ & M & $\mathrm{N}$ & $\mathrm{O}$ & $\mathrm{P}$ \\
\hline Rata- rata Reduksi & & 13,3 & & \multicolumn{9}{|c|}{11.09} & \multicolumn{4}{|c|}{8,41} \\
\hline
\end{tabular}

Daerah kolom yaitu zona 1 dan zona 2 mampu mereduksi lebih besar daripada zona 3.

\section{Perbandingan hasil pengujian kuat tekan bebas}

Gambar 5 menunjukkan nilai kuat tekan tanah (qu) antara tanah tanpa kolom, tanah dekat kolom, dan tanah jauh dari kolom.
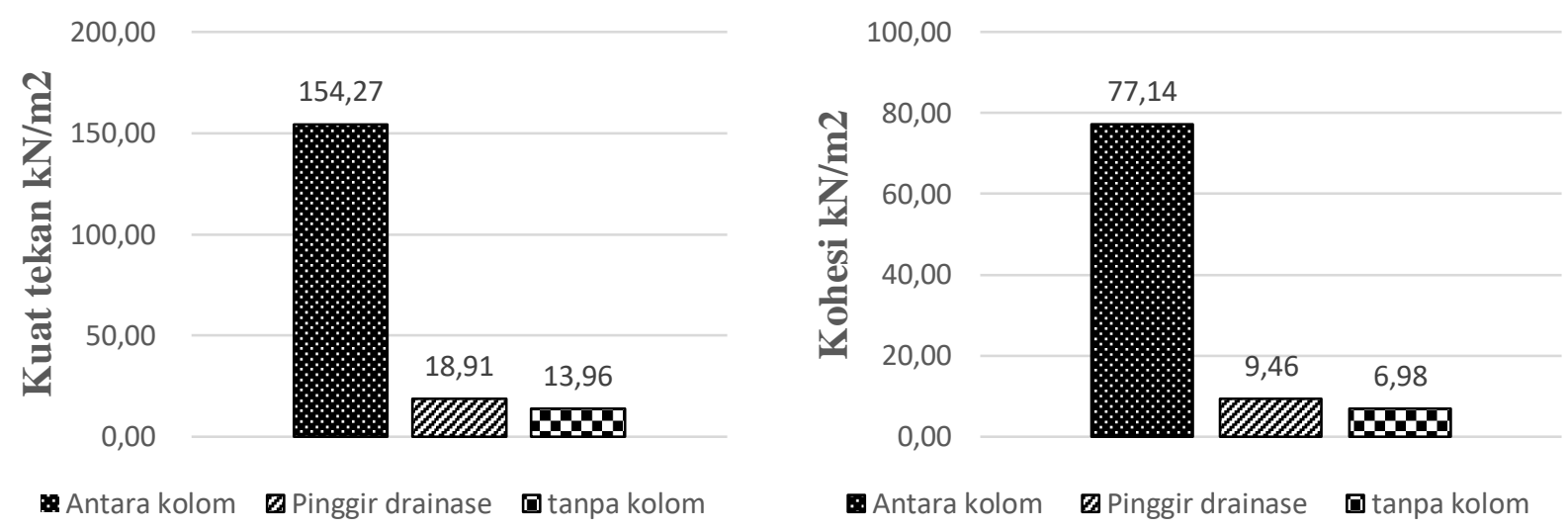

Gambar 5 Perbandingan kohesi dan kuat tekan antara tanah tanpa kolom dan dengan kolom garam

Penambahan kolom garam menurunkan nilai batas cair (LL) dan menaikkan nilai batas plastis (PL), selisih dari nilai batas cair (LL) dan nilai batas plastis (PL) digunakan untuk mencari nilai PI. Penambahan kolom garam menurunkan nilai indeks plastisitas. Nilai batas susut (SL) tanah ekspansif didapatkan sebesar 18,29\%. Hasil pengujian atteberg limits menunjukkan bahwa tanah dengan perkuatan kolom mengurangi sifat kembang susut dari tanah ekspansif. Pengujian kuat tekan tanah pada tanah tanpa perkuatan kolom garam diperoleh nilai kuat tekan sebesar $9,46 \mathrm{kN} / \mathrm{m}^{2}$. Titik pengambilan jauh dari kolom diperoleh nilai sebesar $18,91 \mathrm{kN} / \mathrm{m}^{2}$ dan ini merpakan nilai $q u$ tertinggi. Pada titik pengambilan dekat kolom diperoleh nilai sebesar $77,14 \mathrm{kN} / \mathrm{m}^{2}$ dan ini merpakan nilai $q u$ tertinggi.

\section{Perbandingan hasil pengujian batas konsistensi tanah (Atteberg Limit)}

Tabel 2 Perbandingan Atteberg limits tanpa kolom dan dengan kolom garam

\begin{tabular}{clccc}
\hline No & Jenis Pengujian & Satuan & Tanah Tanpa Kolom Garam & $\begin{array}{c}\text { Tanah dengan } \\
\text { Kolom Garam }\end{array}$ \\
\hline 1 & Batas cair, LL & $\%$ & 114,05 & 110,26 \\
2 & Batas plastis, PL & $\%$ & 42,29 & 51,15 \\
3 & Indeks Plastis, PI & $\%$ & 71,76 & 59,11 \\
\hline
\end{tabular}

Penambahan kolom garam menurunkan nilai batas cair (LL) dan menaikkan nilai batas plastis (PL), selisih dari nilai batas cair (LL) dan nilai batas plastis (PL) digunakan untuk mencari nilai PI. Penambahan kolom garam menurunkan nilai indeks plastisitas. Nilai batas susut (SL) tanah ekspansif didapatkan sebesar 18,29\%. Hasil pengujian Atteberg limits menunjukkan bahwa tanah dengan perkuatan kolom mengurangi sifat kembang susut dari tanah ekspansif. 


\section{Penyebaran garam}

Tabel 3 Pengujian kandungan mineral tanah setelah 20 hari

\begin{tabular}{cccc}
\hline \multirow{2}{*}{ No } & Nama & \multicolumn{2}{c}{ Kandungan dalam tanah } \\
& Kimia & Sebelum pengujian & $38,49 \%$ \\
\hline 1 & $\mathrm{SIO} 2$ & $33,83 \%$ & $19,69 \%$ \\
2 & $\mathrm{Fe} 2 \mathrm{O} 3$ & $20,84 \%$ & $8,46 \%$ \\
3 & $\mathrm{Na} 2 \mathrm{O}$ & $12,97 \%$ & $7,76 \%$ \\
4 & $\mathrm{CaO}$ & $10,57 \%$ & $11,98 \%$ \\
5 & $\mathrm{AlO} 3$ & $9,66 \%$ & $3,06 \%$ \\
6 & $\mathrm{MgO}$ & $3,41 \%$ & $1,36 \%$ \\
7 & $\mathrm{TiO} 2$ & $1,75 \%$ & $0,9 \%$ \\
8 & $\mathrm{~K} 2 \mathrm{O}$ & $1,58 \%$ & $3,64 \%$ \\
9 & $\mathrm{Cl}$ & $0,86 \%$ & $4,66 \%$ \\
10 & $\mathrm{Dll}$ & $4,53 \%$ & \\
\hline
\end{tabular}

Tabel 3 menunjukkan bertambahnya mineral CL pada kandungan tanah sedangkan mineral montmorillonite bertambah. Kesimpulan sementara bahwa garam dari kolom berhasil menyebar kedalam tanah ekspansif tetapi hal ini tidak bernading lurus dengan pengujian sifat fisik tanah setelah ditambahkan kolom garam.

\section{Kesimpulan}

Kesimpulan yang diperoleh dari hasil penelitian dan analisis yang dilakukan diantaranya adalah sebagai berikut :

1. Penambahan kolom garam dapat mengurangi rata-rata swelling sebesar 10,85\% karena garam dapat menambah kohesi antarpartikel sehingga ikatan antar partikel lebih rapat,

2. Penambahan kolom garam pada tanah ekspansif dapat meningkatkan kohesi sebesar dari $6,98 \mathrm{kN} / \mathrm{m}^{2}$ menjadi $77,14 \mathrm{kN} / \mathrm{m}^{2}$ dan meningkatkan kuat tekan dari $13,96 \mathrm{kN} / \mathrm{m}^{2}$ menjadi154,27 kN/m²,

3. Penambahan kolom garam pada tanah ekspansif dapat Penambahan kolom garam pada tanah ekspansif dapat menurunkan nilai PI dari 71,76 \% menjadi 59,11 \% karena kandungan ion pada garam menghalangi ikatan antar partikel tanah dengan air sehingga partikel tanah lebih mudah terlepas dari ikatannya,

4. Garam pada kolom menyebar dengan merata dengan penambahan nilai $\mathrm{Cl}$ dari $0,86 \%$ menjadi 3,64 \%.

\section{Daftar Pustaka}

Bowles, J.E. 1985. Sifat-sifat Fisis dan Geoteknis Tanah (Mekanika Tanah) Edisi Kedua. Jakarta: Penerbit Erlangga. Hardiyatmo, H.,C., 2014, Permasalahan dan Penanganan Tanah Ekspansif, Yogyakarta : Gajah Mada University Press. Herman., 2015, Pengaruh Garam Dapur (NaCl) terhadap Kembang Susut Tanah Lempung, Padang : Institut Teknologi Padang.

Ingles and J. B. Metcalf., 1972, Soil stabilization : principles and practice : Butterwords

Sudjianto, A., T., 2007, Stabilisasi Tanah Lempung Ekspansif dengan Garam Dapur (NaCl), Jurnal: Universitas Widyagama Malang. 